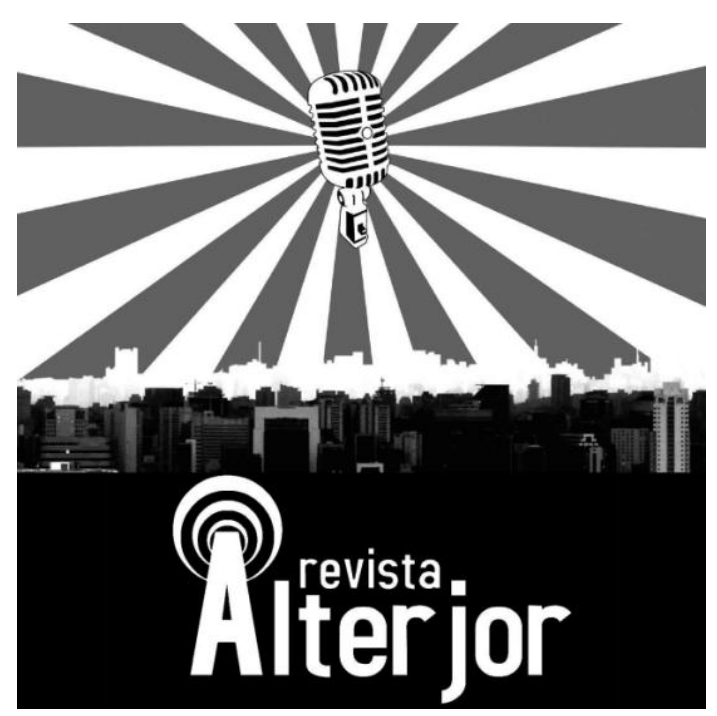

DOSSIê: "Comunicação nas Periferias"

\title{
O JORNALISMO COMUNITÁRIO, A DEMOCRACIA E AS IDENTIDADES INDIVIDUAIS E COLETIVAS
}

\author{
Giuliano Tonasso Galli ${ }^{1}$
}

RESUMO: Este artigo destaca o direito à informação e a liberdade de expressão como fundamentais para o cumprimento efetivo de ideais intrínsecos à democracia. Os meios de comunicação tradicionais, na forma como se configuram, não são capazes de representar uma parte da população, que não se encaixa naquilo que os próprios veículos e seus anunciantes estabelecem como perfil de público-alvo e de consumidor em potencial. Com isso, cidadãos acabam sendo solenemente obliterados de várias práticas comunicacionais, em especial jornalísticas. No sentido de retratar os acontecimentos relativos a uma determinada região, este artigo ressalta o jornalismo comunitário como um poderoso instrumento de representação social, de expressão e de discussão de valores de um grupo, ocupando uma lacuna deixada pela imprensa de grande porte.

PALAVRAS-CHAVE: Jornalismo comunitário. Comunicação popular. Representação.

ABSTRACT: This present paper highlights the right to information and freedom of expression as fundamental to the effective fulfillment of ideals intrinsic to democracy. The traditional media, as currently configured, are not capable to represent a part of the population, which does not fit into what the vehicles themselves and their advertisers establish as a profile of the target audience and potential consumer. As a result, citizens end up being solemnly obliterated from various communication practices, especially journalistic ones. In order to portray the events related to a certain region, this article emphasizes community journalism as a powerful instrument of social representation, expression and discussion of the values of a group, occupying an empty space left by the traditional press.

KEYWORDS: Community journalism. Popular communication. Representation.

\footnotetext{
${ }^{1}$ Mestrando em Ciências da Comunicação e graduado em Jornalismo pela Escola de Comunicações e Artes da Universidade de São Paulo (ECA-USP). É especialista em Direitos Humanos, mais especificamente no direito à Liberdade de Expressão, e representa o Instituto Vladimir Herzog na Comissão Permanente do Direito à Liberdade de Expressão do Conselho Nacional de Direitos Humanos. E-mail: giulianotgalli@gmail.com.
}

Revista AL TERJOR

Grupo de Estudos Alterjor: Jornalismo Popular e Alternativo (ECA-USP)

Ano 10 Volume ol Edição 23 Janeiro-Julho de 2021

Avenida Professor Lúcio Martins Rodrig̉ues, 443, Cidade Universitária, São Paulo, CEP: 05508-020 


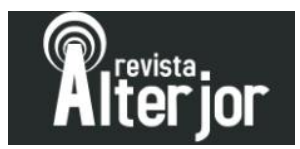

\section{INTRODUÇÃO}

Todo grupo social está obrigado a tomar decisões que terão vigência para todos os seus membros com o objetivo, primeiramente, de garantir a própria sobrevivência, tanto interna como externamente. Nesse sentido, a democracia representa um conjunto de regras e procedimentos para a formação dessas definições coletivas, em que está prevista e facilitada a participação mais ampla possível dos interessados nesse processo. Dessa forma, na medida em que se configura numa garantia de respeito aos direitos, de expressão dos conflitos, de retificação dos caminhos equivocados e de isonomia na punição dos erros, a democracia deve ser valorizada e defendida por todos os cidadãos.

É bem verdade que existem, ainda hoje, diversas sociedades autoritárias, mas que não se apresentam como modelos para as demais, nem são vistas pelo resto do mundo como referência desejável para o desenvolvimento futuro. São situações peculiares, resultantes de desenvolvimentos históricos próprios, que não constituem exemplos universalizáveis de organização política, nem se baseiam em doutrinas generalizáveis ou, sequer, defensáveis. O fato é que não há regimes alternativos à democracia que sejam aceitos majoritariamente na discussão política contemporânea, e as formas autoritárias de governo ou de organização social tendem a ficar isoladas.

Cabe salientar que a linguagem política é notoriamente ambígua. A maior parte dos termos usados no discurso político tem significados diversos. Essa variedade depende tanto do fato de muitos termos terem passado por longa série de mutações históricas, como da circunstância de não existir, até hoje, uma ciência política tão rigorosa que tenha conseguido determinar e impor, de modo unívoco e universalmente aceito, o significado dos termos habitualmente mais utilizados. A maior parte desses termos é, inclusive, derivada da linguagem comum e conserva a fluidez e a incerteza desse contexto. Diante disso, há inúmeros caminhos e é possível se apegar a diversos aspectos para se definir e diferenciar a democracia das demais formas de governo. Mas 


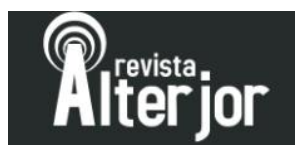

um debate contemporâneo em torno do conceito e do valor da democracia não pode prescindir de uma referência, ainda que rápida, à tradição.

Na teoria contemporânea da Democracia confluem três grandes tradições do pensamento político: a) a teoria clássica, divulgada como teoria aristotélica, das três formas de Governo, segundo a qual a Democracia, como Governo do povo, de todos os cidadãos, ou seja, de todos aqueles que gozam dos direitos de cidadania, se distingue da monarquia, como Governo de um só, e da aristocracia, como Governo de poucos; b) a teoria medieval, de origem romana, apoiada na soberania popular, na base da qual há a contraposição de uma concepção ascendente a uma concepção descendente da soberania conforme o poder supremo deriva do povo e se torna representativo ou deriva do príncipe e se transmite por delegação do superior para o inferior; c) a teoria moderna, conhecida como teoria de Maquiavel, nascida com o Estado moderno na forma das grandes monarquias, segundo a qual as formas históricas de Governo são essencialmente duas: a monarquia e a república, e a antiga Democracia nada mais é que uma forma de república, onde se origina o intercâmbio característico do período pré-revolucionário entre ideais democráticos e ideais republicanos e o Governo genuinamente popular é chamado, em vez de Democracia, de república (BOBBIO, 1998, p. 319).

O problema da democracia, das suas características, de sua importância é, como se vê, antigo. Tão antigo quanto a reflexão sobre as coisas da política, tendo sido reproposto e reformulado em todas as épocas. No intuito de reforçar as diferenças entre as formas democráticas e não democráticas de governo, o pensador italiano Norberto Bobbio nos diz que é possível perceber alguns requisitos essenciais que caracterizam e são inerentes às primeiras. Bobbio entende que, para que haja uma democracia representativa moderna, é imprescindível que existam e funcionem diversas outras instituições políticas básicas, como eleições livres, justas e frequentes, governantes eleitos, autonomia para associação, ausência de um controle estrangeiro hostil e, no mesmo grau de relevância, liberdade de expressão e fontes de informação diversificadas. É uma condição da democracia que os cidadãos tenham acesso a informações independentes e contribuam para que essas informações circulem livremente, que as pessoas participem realmente da vida política, e que adquiram uma compreensão esclarecida das ações do governo. 
Para adquirir competência cívica, as pessoas devem ter o direito de se manifestar, inclusive sobre questões políticas, fazendo críticas ao regime, ao governo, aos funcionários, à ordem socioeconômica e à ideologia dominante. Mais do que isso, precisam expressar seus pontos de vista, aprender umas com as outras, discutir, decidir, questionar especialistas e políticos. É pela liberdade de expressão e pela diversificação das fontes de informação que as pessoas podem - e devem - influenciar as decisões e ações do governo (BOBBIO, 1998, p. 193).

Em outras palavras, para a existência de uma ordem democrática pressupõe-se, entre outros fatos, o controle de um poder pelo outro, sendo todos fiscalizados pelo povo, que é de onde emana a força do Estado existente. Para isso, entretanto, se faz necessário o conhecimento, por parte dos cidadãos, dos fatos, atos ou omissões acontecidas, já que só assim será possível a formação de opinião para poder distinguir e julgar as políticas públicas adotadas. Ou seja, sem o livre fluxo de informações e de opiniões, o regime democrático não funciona.

A esse respeito, é inevitável lembrar que formas de governo antidemocráticas condenam a contraposição de ideias, de opiniões, tal como faziam o nazismo e o fascismo, que pretendiam suprimir as contradições, em nome de uma suposta unidade nacional. A democracia, nesse sentido, é também um meio de resolver conflitos, porque aceita a divergência, a pluralidade, e renuncia à unanimidade.

A Constituição Federal do Brasil, promulgada em outubro de 1988, institui no país um Estado democrático de direito e determina, em seu artigo $1^{\circ}$, parágrafo único, que "todo o poder emana do povo, que o exerce por meio de representantes eleitos ou diretamente"2. Da leitura desse dispositivo, fica fácil deduzir que os constituintes reservaram à sociedade a titularidade do poder do Estado, inferindo-se daí que toda atuação estatal deve se dar em função e em nome do povo, já que é esse o grande legitimador de sua atuação. A lei brasileira ampliou o exercício de direitos, a fim de

\footnotetext{
${ }^{2}$ BRASIL. Constituição (1988). Constituição da República Federativa do Brasil. Brasília, DF: Senado, 1988.
} 


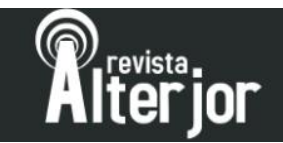

proporcionar a efetiva consagração do processo de cidadania. Nunca antes, em toda a história do país, a preocupação com os direitos fundamentais foi tão marcante e acentuada, mesmo porque o Brasil havia acabado de superar um período de exceção extremamente dramático - o período da ditadura militar, entre 1964 e 1985, marcado, entre outras adversidades, pelo cerceamento das liberdades públicas.

Muito antes da Constituição brasileira, o direito à comunicação vem sendo proclamado como fundamental desde as primeiras declarações de direitos no século XVIII. Ao longo das décadas, a consolidação desse direito foi sendo acompanhada pelo surgimento de outros princípios jurídicos aplicáveis, entre os quais, o direito à informação - que inclui o direito de cada indivíduo em informar, se informar, e ser informado - e a liberdade de imprensa - liberdade de dizer, escrever, documentar e veicular aquilo que é de interesse público. Assim, a ampliação dos direitos no âmbito da comunicação abriu caminhos para o entendimento da própria comunicação como um direito. Na prática, isso significa que todos os cidadãos devem poder e devem ter condições para se expressar livremente, para produzir informação e para fazer circular essas manifestações, sejam elas notícias jornalísticas, opiniões, produções culturais etc. Portanto, não basta ter liberdade de expressão ou acesso a uma vasta gama de fontes de informações. É preciso que Estado e sociedade adotem medidas para garantir que todos possam exercer esse direito plenamente.

O que se vê, no entanto, é que essa noção ainda é muito pouco explorada no Brasil. Apesar de indiscutivelmente democrática, os artigos da Constituição brasileira que tratam do tema são raros e carecem de regulamentação, o que dificulta seu reconhecimento. O Estatuto da Juventude, lei em vigor desde outubro de 2013 e que determina quais são os direitos dos jovens que devem ser garantidos e promovidos pelo Estado brasileiro, independente de quem esteja à frente da gestão dos poderes públicos, talvez seja o instrumento legal que melhor trate da comunicação como, de fato, um direito. Em seu artigo 26, estabelece que "o jovem tem direito à comunicação e à livre 


\section{Ritieior}

expressão, à produção de conteúdo, individual e colaborativo, e ao acesso às tecnologias de informação e comunicação"3.

Ainda assim, nos encontramos longe de tratar o direito à informação no nível dos demais direitos - como a educação ou a saúde -, o que se revela absolutamente pernicioso: onde esse direito não se faz respeitar integralmente, a liberdade necessária para bem informar a sociedade não pode ser exercida plenamente. $\mathrm{O}$ fato é que quanto mais inclusiva, mais a democracia se empenha em expandir o universo dos que têm acesso à informação e, assim, assegura a transparência na concepção, elaboração e acompanhamento das políticas públicas. Quanto mais vigorosa, mais a democracia faz circular as ideias.

\section{O papel do jornalismo}

Apesar da indiscutível relevância conferida ao direito de informação e de comunicação, muitos dos textos-chave da fundação da teoria democrática, ou das próprias práticas democráticas, não fazem quaisquer referências ao jornalismo. Não havia imprensa na Grécia Antiga e, mais tarde, para os inspiradores das revoluções americana e francesa, era secundário o papel que esse meio desempenhava, muito embora fizessem uso de panfletos impressos e até de jornais. Apenas numa fase mais recente é que os próprios jornalistas passaram a reivindicar a importância crucial da sua atuação para o bem comum: a liberdade de expressão. Assim, em sociedades que se postulavam como liberais, já se mostrava óbvia a necessidade específica do jornalismo e dos jornalistas para a democracia.

3 BRASIL. Lei $\mathrm{n}^{\circ}$ 12.852, de 5 de agosto de 2013. Institui o Estatuto da Juventude e dispõe sobre os direitos dos jovens, os princípios e diretrizes das políticas públicas de juventude e o Sistema Nacional de Juventude. Diário Oficial da União. Brasília, DF, 6 de agosto de 2013. Seção 1, p. 3. 


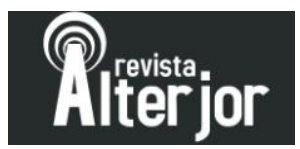

Isso decorre, acima de tudo, naquela que talvez seja a afirmação mais comum sobre a função da imprensa em um regime democrático: a notícia jornalística possui um papel vital na tarefa de informar o público e, consequentemente, na realização do ideal de circulação das informações. Mas não é apenas isso. O jornalismo é fundamental na investigação dos diversos agentes de poder, entre eles o poder político. Tem a função de análise, através da qual devem ser fornecidos quadros de interpretação que tornem compreensíveis e coerentes aspectos mais complexos da sociedade. "Deve transmitir histórias de interesse humano, providas de diferentes pontos de vista e modos de vida que compõem o mundo" (DINES, 2009, p. 79). Em suma:

\begin{abstract}
O jornalismo demarcou para si um campo situado fora do Estado, tornando-se independente do governo. A partir daí, exerce sua tarefa primordial: vigiar o poder por meio da investigação e disseminação das notícias e das ideias de interesse público, promovendo o diálogo entre os integrantes do espaço público (BUCCI, 2006, p. 47).
\end{abstract}

Há, portanto, uma responsabilidade dos meios para com a sociedade democrática, independente se esses meios são públicos ou privados, pois embora sejam instituições livres, prestam contas à Justiça e aos cidadãos. No entanto, embora o jornalismo seja uma valorosa forma do direito à informação, não é a única: quando os cidadãos não têm uma determinada informação necessária, há um problema, e o Estado deve oferecê-la da mesma maneira como deve fornecer outros serviços de natureza social.

Um veículo jornalístico - mais uma vez, independentemente se público ou privado, se bem-sucedido, tem, fundamentalmente, a cara do público ao qual se dirige, afinal é a esse público que ele presta serviços. Dessa forma, torna-se absolutamente compreensível que o conteúdo produzido pelo jornalismo fale da realidade das pessoas que o consome, como sendo aquela toda a realidade imediata que interessa. 


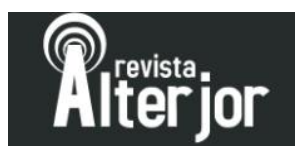

Assim, é possível observar uma distância entre o âmbito social dos meios e o âmbito social das reivindicações de direitos sociais, num afastamento que se traduzirá na limitada preocupação dos veículos jornalísticos com o segundo contexto. Em linhas gerais, o âmbito dos meios abrange o circuito constituído por editores, jornalistas e, obviamente, pelos leitores. Já o âmbito das reivindicações sociais é composto, via de regra, pelos pobres, pelos marginalizados pelas políticas públicas, pelos moradores dos bairros periféricos. Portanto, é possível supor que, em parte, os temas sociais não frequentem as preocupações de diretores de jornais, jornalistas e mesmo dos leitores por uma questão, basicamente, de pertencimento social.

O problema da sub-representação das questões da cidadania social é que ela fere o ideal democrático de expansão do direito à comunicação. Além disso, decorre também da natureza do jornalismo praticado num contexto de mercado, focalizado em critérios de noticiabilidade que privilegiam os acontecimentos pontuais, as pessoas influentes, $o$ número, o impacto imediato; e não os processos de longa duração. Nesse caso, as camadas mais pobres da sociedade só alcançariam visibilidade no noticiário em ocorrências pontuais extremas: acidentes, chacinas, confrontações, calamidades, ocupações etc. No entanto, cessadas as circunstâncias imediatas do acontecimento, o assunto tende a desaparecer do noticiário ou a restringir-se a pequenas notas.

Como se não bastasse, a publicidade - presente tanto em meios públicos, como em meios privados - encoraja essa mudança da diversidade da informação e acaba por agir em favor dos anunciantes; e contra os cidadãos. É possível dizer que ao tratar a comunicação e seus agentes como um mercado, os veículos jornalísticos restringem a liberdade de comunicação e impõem barreiras à cidadania. Em outras palavras, o consumidor se sobrepõe ao cidadão, e os indivíduos são tratados como consumidores liderados pelo mercado; e não como cidadãos ativos com direitos e obrigações. 


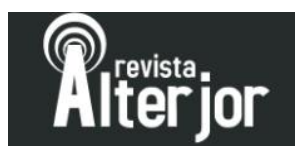

O liberalismo de mercado interpreta a liberdade de imprensa como o resultado de uma luta longa e heroica de empreendedores privados para se libertarem das obrigações e restrições que o governo ou o público podiam tentar impor. O problema é que o liberalismo de mercado não mostra que os mercados são estruturas complexas dentro das quais os tomadores de decisão corporativa agem como censores. A competição de mercado produz a censura de mercado. (KEANE, 1998, p. 90).

É possível verificar, portanto, que há uma lacuna na forma como o jornalismo organiza a produção de seus conteúdos atualmente, e que há um numeroso grupo de pessoas que não estão no foco do público para o qual os veículos direcionam suas realizações. Não é exagero dizer, assim, que o jornalismo tem fraquejado na sua tarefa de informar a totalidade dos cidadãos e, consequentemente, na concretização do ideal democrático de livre e extensa circulação das informações.

No sentido de corrigir essa falha, destaca-se a atuação do jornalismo comunitário, que se torna uma possibilidade para parte da população encontrar espaço e discutir assuntos que são de seu interesse, mas que nos grandes veículos de comunicação não são abordados e, quando o são, o viés não é o desejado. Além disso, essa modalidade de jornalismo ajuda - numa contribuição também imensamente valiosa para a democracia - na socialização de cidadãos que normalmente não são protagonistas nas atuações e nas narrativas do jornalismo tradicional, uma vez que promove "a humanização e a realização do sujeito como um indivíduo, sendo esse um espaço de individual que já não é mais possível na sociedade que tende a cada vez mais nivelar as pessoas, deixando-as na generalidade” (MARCONDES FILHO, 1987, p. 26).

Por jornalismo comunitário podemos compreender, em linhas gerais, a atuação da profissão jornalística voltada aos fatos que ocorrem dentro de uma comunidade, ou que sejam de interesse para seus moradores. Também se define como o jornalismo praticado por membros de uma comunidade, como, por exemplo, nos casos mais emblemáticos e de maior conhecimento da sociedade, de jornais e rádios produzidos por 
moradores de uma favela, ou de um bairro periférico com deficiência na implementação de políticas públicas de incremento da cidadania.

Uma imprensa só pode ser considerada comunitária quando se estrutura e funciona como meio de comunicação autêntico de uma comunidade. Isto significa dizer: produzido pela e para a comunidade. Seu perfil é o de uma imprensa feita para a comunidade, comprometida com o fortalecimento das identidades locais (MELO, 2006, p. 142).

A princípio, pode-se afirmar que sempre existiu o jornalismo voltado para a comunidade, antes até de assuntos de âmbito nacional ou mundial. Mas o jornalismo comunitário como é conhecido atualmente foi intensamente impulsionado pelo advento das novas tecnologias de comunicação, em especial a internet, que tornaram mais acessível a produção de conteúdo.

Importante salientar que o jornalismo comunitário não é e nem tem a pretensão de ser uma forma de comunicação desenvolvida para repudiar a mídia massiva - o que talvez fosse natural entre aqueles que, ao verificarem que o ideal democrático de livre circulação das informações não vem sendo cumprido, se preocupam em assegurá-lo. Nesse sentido, convém não esquecer que tanto "comunitário", "participativo" ou "popular" não qualificam necessária e automaticamente o substantivo democracia. Muitas organizações podem estar às voltas com propostas conservadoras e autoritárias. O Brasil está cheio de exemplos. Os movimentos populares também são atravessados pelas contradições de classe e de projetos de sociedade que disputam a hegemonia no mundo e em nosso país. O jornalismo comunitário também possui desafios semelhantes e qualquer análise deve, obrigatoriamente, levar em consideração as peculiaridades desta forma de comunicação, que certamente são substancialmente diversas e complexas.

\section{Todos se sentem mal representados}


A força da comunicação contemporânea deve-se, em grande medida, às capacidades expressivas dos meios de informação que, por meio das imagens e da palavra, conferem realismo, drama e intensidade afetiva às representações midiáticas. Na sua origem e etimologia, o conceito de representação evoca algum tipo de simulação das propriedades de objetos, eventos, processos e relações, com a finalidade de retratálos. As representações teriam, dessa forma, um caráter analógico à realidade.

A semelhança entre um objeto ou um acontecimento e sua respectiva imagem ou relato assegura um caráter testemunhal, uma verossimilhança e um realismo às representações, dando um ar de naturalidade e espontaneidade a essas formas. Essas características foram exponencialmente aumentadas pelo cinema e, mais ainda, pela televisão, especialmente nas transmissões ao vivo, que agregaram à imagem visual o movimento, os sons da realidade e a simultaneidade. Por essa razão, é importante se empenhar no sentido de revelar o caráter construído das representações que, apesar de naturalmente óbvio, não é absolutamente evidente.

Qualquer análise da ideia de representação deve partir, necessariamente, do reconhecimento desse caráter produzido. No entanto, as marcas dessa produção podem ser esquecidas sutilmente, ficando invisíveis - tanto no caso das imagens, como no caso dos discursos verbais. Como aparentam ser, ou mesmo se apresentam como um retrato do mundo, essas representações sancionam, homologam e naturalizam certos vieses que, no âmbito discursivo, sugerem que esse é o modo de ser da sociedade representada. Assim, podem, perigosamente, servir para, por exemplo, fixar ou confirmar estereótipos étnicos, sociais, de gênero, profissionais, além de instaurar padrões ou modelos, e reproduzir imagens pejorativas ou idealizadas. 


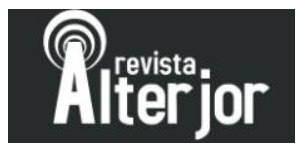

As representações podem aparecer no contexto discursivo como formas casuais, meras insinuações, pistas visuais, ou mesmo como cenário dado como normal ou padrão. Os discursos, assim, produzem determinadas composições, colhidas no mundo empírico, aparentemente sem intervenção ativa de ninguém, que são elevadas à categoria de representantes de pessoas, situações e fatos. Nesse sentido, as intervenções do autor de um discurso também são potencialmente capazes de influenciar, ainda que de maneira sutil, as percepções do leitor.

É necessário deixar claro que, apesar de sempre relacionadas à comunicação, as representações desempenham papeis distintos nos três grandes gêneros da cultura midiática - a ficção, a publicidade e o jornalismo. Em todos esses casos, as consequências da forma como os discursos são construídos são muito mais duradouras e significantes do que uma simples e despretensiosa representação. Pode-se dizer que telenovelas, séries de TV, filmes e outras obras ficcionais do âmbito da fabulação produzem um imaginário sem compromisso obrigatório com o mundo empírico e histórico. Mas, mesmo nesses casos, ainda que se baseiem na liberdade criativa dos autores, as produções constroem representações tácitas sobre a realidade social, naturalizando as estruturas sociais vigentes, idealizando algumas categorias e demonizando outras.

Algo semelhante acontece na publicidade, gênero que financia toda a comunicação midiática e que possui objetivos bem específicos, normalmente a fim de despertar nas audiências o desejo de consumo de bens. A representação, aqui, organizase de forma retórica e trabalha no sentido de semantizar mercadorias, às quais atribui significados hiperbólicos. Para isso, opera, na maioria das vezes, com elementos narrativos que recaem, geralmente, na reiteração do status quo, o que acaba por envolver, entre diversos exemplos, a idealização de famílias felizes, sexualidade, beleza e juventude perpétuas etc. Apesar disso, se aceita com relativa naturalidade a ideia de que um filme de ficção ou um comercial de TV contenham representações construídas e que sigam as tendências de sua época. Mas é difícil admitir essa inclinação quando se trata de uma produção jornalística. Isso se deve, principalmente, à suposição de um 


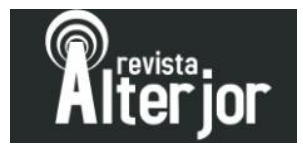

compromisso ético e profissional, específico desse gênero, em estabelecer uma relação referencial com a realidade. No entanto, o jornalismo é necessariamente um relato particular dos acontecimentos, ou seja, uma narrativa construída sobre um aspecto do mundo selecionado, e a forma com que esses aspectos - e não outros - são selecionados pode gerar controvérsias.

De forma geral, o jornalismo e a atuação dos jornalistas são alvos costumeiros das mais variadas críticas. Em relação a isso, esquerda e direita, sociedade civil e governo, ricos e pobres sempre têm algo a reclamar, embora certamente em proporções diferentes e por motivos distintos. Uma atividade que se desenvolve na esfera pública social, e que adquiriu tamanha importância no contexto democrático, entretanto, não poderia estar imune a tal consequência. As reclamações fazem parte da conjuntura de liberdade e pluralidade em que o jornalismo se construiu e está inserido na contemporaneidade.

No centro de toda essa discussão está o principal produto jornalístico: a informação, sem a qual seria impossível imaginar a vida em sociedade. A informação é o resultado da mediação jornalística que possibilita ao público o conhecimento dos fatos atuais. É especialmente em relação ao trabalho de produção informativa que diferentes grupos e indivíduos se manifestam, julgando positiva ou negativamente o desempenho dos jornalistas e do jornalismo em geral. Como dito anteriormente, representações não são informações pontuais, tão somente. Por isso, o jornalismo permite que informações pontualmente corretas e verificáveis sejam selecionadas, valorizadas, destacadas, omitidas ou atenuadas, relacionadas a outras, de modo a produzirem representações diferentes de uma mesma situação, dentro do limiar exigido de verossimilhança e de compromisso com a verdade.

Ao fornecerem, repetirem e, portanto, reforçarem palavras e imagens que referenciam alguns vieses, mas não outros, os enquadramentos das produções 


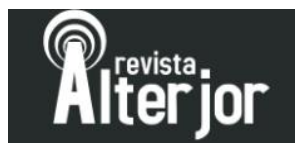

jornalísticas tornam algumas ideias mais salientes no texto, outras menos e outras, ainda, inteiramente invisíveis. As orientações dos enquadramentos são difíceis de detectar porque muitos artifícios podem parecer naturais, simples escolhas de palavras ou imagens. A comparação com outros textos, no entanto, mostra que essas escolhas não são inevitáveis, tampouco deixam de ser problemáticas, sendo, pelo contrário, modos de definir e interpretar os acontecimentos e as informações.

Essa capacidade que o discurso jornalístico possui de dar diferentes destaques a diversos enquadramentos possíveis e de transitar sobre uma mesma informação - sem, evidentemente, fugir da verdade e do compromisso com o interesse público, faz com que todos se sintam mal representados e reivindiquem uma melhor representação nos discursos jornalísticos, independente de classe social, renda, status, poder adquirido etc. Isso não significa, de maneira nenhuma, que o jornalismo tem se revelado capaz de representar todos os grupos da sociedade de forma proporcional, justa e equivalente. E é justamente a partir dessa incapacidade, que a própria atividade jornalística tenta, historicamente, se reorganizar e encontrar alternativas para concretizar o seu ideal democrático de expandir o interesse e o acesso dos cidadãos à informação.

\section{Para quem fala o jornalismo?}

Um veículo jornalístico, se bem-sucedido, tem a cara do seu leitor. A ele, afinal, presta serviços. Até por isso, é comum verificar o interesse das empresas de comunicação em conhecer o seu público. Para ilustrar esse ponto, cabe citar a edição da Folha de S. Paulo de 11 de novembro de 2012, em matéria intitulada: "Leitor da Folha está no topo da pirâmide social brasileira". Diz o texto, que reproduz uma pesquisa do Datafolha, agência de pesquisas do jornal:

O leitor da Folha está no topo da pirâmide da população brasileira: $68 \%$ têm nível superior (no país, só $11 \%$ passaram pela universidade) e $90 \%$ 


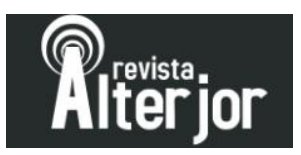

pertencem às classes A e B (contra 18\% dos brasileiros). A maioria é branca, católica, casada, tem filhos e um bicho de estimação. A maior parcela dos leitores tem entre 23 e 49 anos, é usuária de internet, faz exercícios e frequenta restaurantes, shoppings, cinema e livrarias. $O$ leitor é superequipado - tem celular, DVD, computador e câmara digital - e faz uso intenso da internet: a maioria usa buscadores, compara preços, faz pesquisas de trabalho, faz download de programas e ouve músicas. São consumidores vorazes de mídia: $92 \%$ assistem a telejornais, $69 \%$ leem revistas, $58 \%$ ouvem notícias no rádio e $57 \%$ seguem noticiário online. O meio impresso, porém, é o preferido dos entrevistados: se tivessem que optar por um, 53\% ficariam apenas com o jornal (FOLHA DE S. PAULO, 2012) ${ }^{4}$.

Do ponto de vista das estratégias mercadológicas, é recomendado que o jornal procure traçar o perfil do seu público. No entanto, ao visualizar leitores situados numa faixa de renda elevada, com grau de instrução superior, exercendo profissões de status alto, com um estilo de vida marcado pelo consumo sofisticado, usuário de tecnologia avançada, ou seja, com uma inserção social diferenciada do conjunto da sociedade brasileira, a publicação parece sinalizar que a probabilidade de serem agendados certos temas de interesse desse segmento é maior do que outros.

O fato é que enquanto os meios de comunicação tradicionais parecem representar razoavelmente as questões que envolvem interesses do seu público leitor, o mesmo não ocorre com igual intensidade no caso dos mais pobres, dos marginalizados, daqueles que normalmente não são priorizados, na prática, pelas políticas públicas de incremento da cidadania. Ao ignorar, ou ao não tratar com tanto destaque algumas questões sociais, o jornalismo fecha os olhos para uma parcela significativa da realidade com que lida. Cada jornal, cada veículo tem o seu repertório próprio, sua agenda própria, sua audiência própria, mas a partir do momento em que o cidadão não dispõe de meios que o informem com qualidade sobre temas que afetam principalmente os mais pobres, algo não vai bem.

4 LEITOR da Folha está no topo da pirâmide social brasileira. Folha de S. Paulo, São Paulo, 11 de novembro de 2012. Disponível em: http://www1.folha.uol.com.br/poder/2012/11/1834226 (Acessado em 9 de dezembro de 2020).

Revista ALTERJOR

Grupo de Estudos Alterjor:Jornalismo Popular e Alternativo (ECA-USP)

Ano 10 Volume Ol Edição 23 Janeiro-Junho de 202l Avenida Professor Lúcio Martins Rodrig̉ues, 443, Cidade Universitária, São Paulo, CEP: 05508-020 


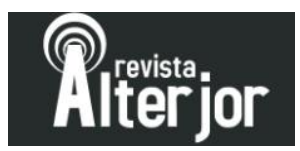

Nesse sentido, é possível dizer que a cobertura é deficitária porque, em parte, os representantes dessa parcela da população não estão entre os leitores das principais publicações do país. Em outras palavras, as questões sociais não figuram tanto na pauta porque quem as reivindica não consome o pacote jornalístico. Não se pode, obviamente, descartar a possibilidade de a cobertura deixar a desejar porque os jornalistas são técnica ou culturalmente despreparados, assim como não pode ser desprezada a origem social dos jornalistas que, em sua imensa maioria, são filhos da classe média que, em sua história de vida, tiveram pouco ou nenhum contato com os cidadãos mais pobres e as áreas em que estes moram. De qualquer forma, o fato é que o público leitor a quem esses jornalistas prestam serviços ainda é quantitativamente reduzido e qualitativamente pouco heterogêneo, não refletindo a composição da sociedade inteira.

Assim, os jornalistas, ao prestarem serviços ao seu público habitual, cumprindo, portanto, o papel de servir ao leitor, atendem apenas a uma parte da sociedade: a parte que os lê. O público com que dialogam é parcial - daí a parcialidade da pauta com que trabalham. Nos grupos de leitores dos diários tradicionais do Brasil, ao menos como regra, não entram a maior parte dos cidadãos das periferias, que não são assinantes, raramente são compradores de exemplares avulsos e também não consomem os produtos anunciados nas páginas de publicidade. Em outras palavras:

Os participantes dos movimentos sociais, em sua maioria, são retratados meramente como terceiros distantes, comparecendo às reportagens como ameaças externas à rotina dos leitores. Considerando ainda que as fontes mais habituais dos jornais emergem dos grupos daqueles que os leem, ou seja, considerando que o conjunto das fontes pertence ao conjunto dos leitores, vê-se também que o diálogo estabelecido, nas páginas dos jornais, também exclui, ao menos como regra, se não todas as lideranças, ao menos os participantes dos movimentos sociais (BUCCI, 2008, p. 55).

Sendo assim, por que é que um jornal lido nos bairros nobres vai abordar, por exemplo, questões acerca de um movimento de favelas? Só se falará disso quando esse movimento afetar a normalidade dos habitantes dos bairros onde se concentram os 


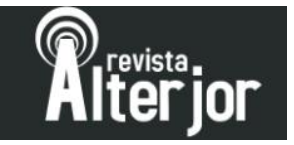

leitores. É mais fácil, na verdade, o lançamento de uma coleção de roupas da moda do verão obter uma página no jornal diário do que uma reportagem sobre habitações populares urbanas conseguir esse destaque.

Como se não bastasse o fato de a questão das habitações populares não estar presente na realidade cotidiana dos leitores tradicionais, ainda entram em jogo os critérios de noticiabilidade das redações jornalísticas. Enquanto a sub-habitação é o cenário secular da sociedade brasileira, ou seja, algo com menor valor para virar uma notícia, já que não tem o fator novidade, os novos modelos de um estilista se apoiam exatamente nesse aspecto. Só em circunstâncias especiais um assunto da esfera da cidadania social impactaria o campo do noticiário da imprensa tradicional.

Esse problema da sub-representação das questões da cidadania social decorre também da natureza do jornalismo praticado num contexto de mercado, focalizado em critérios que privilegiam os acontecimentos pontuais, as pessoas influentes, o número, o impacto imediato; e não os processos de longa duração. Nesse caso, as camadas mais pobres da sociedade só alcançariam visibilidade no noticiário em ocorrências pontuais extremas: acidentes, chacinas, confrontações, calamidades, ocupações. Essas situações se inserem nos critérios de noticiabilidade das redações pelo número de pessoas envolvidas, pela negatividade ou pelo tom emocional das histórias pessoais; e não como indicativos de injustiças, assimetrias sociais, desigualdade de oportunidades e de renda, exclusão histórica, condição de moradia etc.

A responsabilidade social do jornalismo passa por assumir o desafio editorial de expandir e qualificar a base de leitores de notícias, em meios impressos e eletrônicos. Do mesmo modo, passa por separar os critérios que filtram o acesso ao consumo dos critérios de admissibilidade do cidadão à condição de interlocutor do discurso jornalístico (BUCCI, 2008, p. 56). 


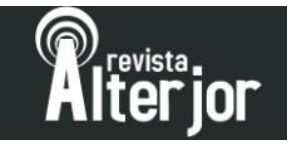

Os parâmetros, os valores e, por vezes, os preconceitos que se verificam nas redações dos meios impressos viram referências - não necessariamente dominantes para a prática do jornalismo em geral. A partir disso, sem cair na armadilha das generalizações, podemos observar que, às vezes, até nos noticiários de televisão essas questões sociais ainda aparecem como a "realidade deles", como se seus protagonistas não compusessem sequer o público telespectador. Diferente dos jornais impressos, a TV não possui assinantes. E seu público, como se sabe, está espalhado por toda a cidade, inclusive nos bairros das periferias. É, portanto, um meio de comunicação, pelo menos no que diz respeito ao acesso, extremamente democrático. O que se observa, no entanto, é que mesmo no jornalismo praticado nas emissoras de televisão as questões sociais são esquecidas, e os moradores dos bairros mais distantes não são devidamente representados.

Há um elemento perverso nessa exclusão: os cidadãos mais pobres, pertencentes a camadas sociais que não têm acesso aos bens de consumo, a despeito de integrarem o amplo espectro de telespectadores, não fazem parte da audiência que possui um considerável poder de compra. Como o consumo serve de baliza para o modo como a publicidade na TV dialoga com o telespectador, esse público, que não chega a ser um consumidor em potencial, termina por se ver estigmatizado, diante da tela, como sendo uma subplateia. Por desdobramento, por mais que os editores de televisão acreditem no contrário, esses segmentos da sociedade acabam não sendo convidados a serem interlocutores do discurso jornalístico da TV. Guardadas as proporções, pode-se considerar a mesma hipótese para uma análise do radiojornalismo. $\mathrm{O}$ não consumidor tende a ser um não interlocutor. Nessa medida, os parâmetros estreitos herdados da tradição dos diários se converteriam num tipo de preconceito perversamente lógico, sustentado pela estratificação imposta pelo consumo.

O fato de não pertencerem ao grupo dos que se comunicam normalmente pelas páginas dos jornais e às camadas sociais com acesso ao consumo é o que mais segrega 


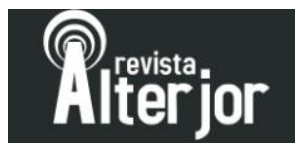

os cidadãos das periferias. E é a partir dessa incapacidade de dialogar com todos os cidadãos, revelada pelo jornalismo tradicional, que o jornalismo local consegue crescer, se desenvolver e contemplar camadas da população que não têm suas reivindicações e sua realidade representadas nos veículos que se propõem a estabelecer um diálogo nacional.

\section{Feita para e pela comunidade}

Entende-se por jornalismo comunitário aquele jornalismo que, em linhas gerais, se dedica ao relato de fatos que atendem às demandas de uma determinada comunidade. Basicamente, é através dele que se busca resgatar a identidade individual e coletiva da sociedade na qual determinada comunidade está inserida. Configura-se também numa forma de busca constante pela valorização da cultura local, de uma coletividade, a partir da noção de pertencimento do indivíduo a uma determinada comunidade, sendo que existem condições básicas para a existência de uma comunidade. São elas:

Um processo de vida comum por meio de relacionamentos orgânicos e certo grau de coesão social; autossuficiência (as relações sociais podem ser satisfeitas dentro da comunidade, embora não seja excludente); cultura comum; objetivos comuns; identidade natural e espontânea entre os interesses e seus membros; consciência de suas singularidades identificativas; sentimento de pertencimento; participação ativa; lócus territorial específico; e linguagem comum (PERUZZO, 2006, p.13).

A conceituação de "comunidade" é imprescindível no entendimento do jornalismo e da comunicação comunitária, mas não há nenhuma condição sine qua non nessa definição. Tal ressalva é válida porque, em tempos de novas tecnologias e de fim de determinadas barreiras quebradas pela internet, nem sempre todas as características estarão presentes, mas nem por isso o conceito de "comunidade" se perde. Ele é, na verdade, reconfigurado. Destacar essa modificação é fundamental porque a própria 


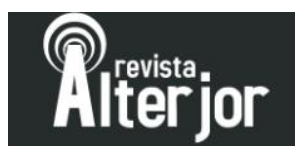

comunicação comunitária se apropriou dessa reconfiguração e se modificou para se estabelecer nos moldes em que está estabelecida atualmente.

A delimitação do termo "comunidade", mesmo não sendo algo fácil ou unânime, é crucial. Quando absorvemos a comunidade e passamos a vê-la como algo que nos pertence, já estamos inseridos nela. É, sem dúvida, o elemento mais forte nessa definição. O pertencimento é o fator que leva à participação ativa, que por sua vez, é o elemento catalisador da comunicação comunitária. Em outras palavras "uma imprensa só pode ser considerada comunitária, quando se estrutura e funciona como meio de comunicação autêntico de uma comunidade. Isto significa dizer: produzido pela e para a comunidade" (MELO, 2006, p. 126).

O jornalismo comunitário é, portanto, a oportunidade de proporcionar aos indivíduos uma cidadania mais ampla, no sentido de poder exercer seu direito a uma comunicação ativa; e não apenas passiva, como já acontece nos meios de comunicação de massa tradicionais, nos jornais de bairro e nos cadernos de bairro. Sendo assim, o cidadão, ao ser inserido em um sistema de comunicação comunitária, tem condições de participar de maneira ativa do processo de construção das produções jornalísticas que culminam com publicação de um determinado veículo comunitário. Essa práxis conduz, cada vez mais, à produção de conteúdos que vão garantir um estreitamento entre o público leitor e a produção das informações. E essa é, sem dúvida, uma forma de garantir maior reciprocidade e respeitabilidade entre o veículo e o público a que ele se destina.

Além de propiciar a participação ativa da população, o jornalismo comunitário também se caracteriza por possuir princípios ligados a valores públicos, coletivos, tais como: não ter fins lucrativos, ter propriedade coletiva e difundir conteúdos com a finalidade de educação, cultura e ampliação da cidadania. Ou seja, também é característico dessa experiência de comunicação o empoderamento das concepções de 


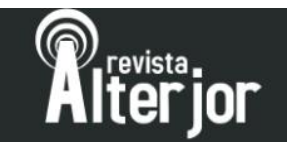

comunidade, a fim de promover iniciativas de transformação e de incremento da cidadania para os seus membros.

Pode-se concluir, portanto, que o jornalismo comunitário se configura numa excelente ferramenta para ampliar o acesso à informação e propiciar uma maior interlocução entre produção e recepção dos conteúdos jornalísticos, permitindo, assim, não apenas a representação da comunidade sem desvios e reprodução de estereótipos, mas também a sociabilidade dos cidadãos.

\section{Não há democracia sem liberdade de expressão e direito à informação}

Ao abordarmos um cidadão na rua e perguntarmos o que ele entende por democracia, provavelmente iremos constatar que sua percepção está ligada ao fato de se tratar de um governo "do povo, pelo povo e para o povo". Não está errado. Mas a expressão, consagrada por Abraham Lincoln", precisa de reparos, uma vez que "pelo povo e para o povo" são instigantes de um pensamento que pode pressupor que há uma instância maior do que o próprio povo na condução dos assuntos da sociedade. E não há. A democracia não é só o que disse o presidente norte-americano. É mais do que uma forma de governo ou um regime político. É mais do que assegurar formalmente direitos fundamentais. É muito mais do que exercer o direito ao voto. Democracia é um conceito múltiplo e variável, que se constrói e se aperfeiçoa com o passar dos tempos, e tem como principal objetivo a convivência harmônica entre os diversos grupos de cidadãos que compõem um Estado.

\footnotetext{
${ }^{5} \mathrm{O}$ "Discurso de Gettysburg" é o mais famoso discurso do presidente dos Estados Unidos, Abraham Lincoln. Foi proferido em uma cerimônia no Cemitério Nacional de Gettysburg, na Pensilvânia, na tarde do dia 19 de novembro de 1863 . Em apenas 272 palavras, ditas em menos de dois minutos, Lincoln invocou os princípios da igualdade da Declaração de Independência e definiu o final da Guerra Civil como um novo nascimento da liberdade, e isso iria trazer a igualdade entre todos os cidadãos, criando uma nação unificada em que os poderes dos estados não se sobrepusessem ao "governo do povo, pelo povo, para o povo".
}

Revista ALTERJOR

Grupo de Estudos Alterjor:Jornalismo Popular e Alternativo (ECA-USP)

Ano 10 Volume Ol Edição 23 Janeiro-Junho de 2021

Avenida Professor Lúcio Martins Rodrig̉ues, 443, Cidade Universitária, São Paulo, CEP: 05508-020 
Entre suas diversas características, nos interessa destacar que onde não há diálogo, não há democracia. Sem liberdade de expressão e sem direito à informação, não há a verdadeira democracia. Mais do que isso: a liberdade de expressão e de informação se constitui em um dos fundamentos essenciais para a constituição de uma sociedade democrática, pois, em última instância, esses valores são indispensáveis para o progresso e o desenvolvimento dos cidadãos. Não à toa, a maior arma de uma ditadura não é o tanque ou o canhão; mas sim a censura.

O Brasil, a partir da Constituição de 1988, restabeleceu a inviolabilidade de direitos e liberdades básicas e instituiu uma vastidão de preceitos progressistas, como a igualdade de gêneros, a criminalização do racismo, a proibição total da tortura e direitos sociais como educação, trabalho, saúde - e informação. Ainda assim, nos encontramos longe de tratar o direito à informação no nível dos demais direitos, e essa realidade é altamente problemática, afinal, onde esse direito não se faz respeitar integralmente, a liberdade necessária para bem informar a sociedade não pode ser exercida plenamente.

No sentido de assegurar esse direito, o jornalismo é protagonista e tem papel fundamental, pois é um dos principais responsáveis por fiscalizar políticos e governos, informar o cidadão, cobrar, denunciar e debater temas da política ou comuns à sociedade. Portanto, é essencial, numa democracia, que exista um jornalismo que, em linhas gerais, busque incansavelmente a isenção e a correção para informar o que está acontecendo para que, a partir disso, o cidadão, informado de maneira ampla e plural, escolha o caminho que quer seguir.

Um veículo jornalístico tem, fundamentalmente, a cara de seu público, afinal, é a ele que se dirige e presta serviços. Isso quer dizer que é compreensível que um meio de informação trate da realidade das pessoas que o consome como sendo a totalidade da 


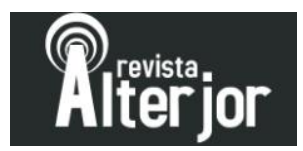

realidade que interessa. No entanto, nessa lógica, uma parcela considerável da população - que não pertence ao mesmo âmbito social daqueles que produzem e consomem o pacote jornalístico - acaba sendo sub-representada pelos veículos tradicionais que estão inteiramente inseridos num contexto de mercado. O problema dessa sub-representação é que ela fere o ideal democrático de direito à informação. Há, portanto, uma lacuna na forma como o jornalismo organiza a produção dos seus conteúdos e há um numeroso grupo de pessoas que não estão no foco do público para o qual os veículos direcionam suas realizações. Dessa forma, não é exagero dizer que o jornalismo tem fraquejado na sua tarefa de informar a totalidade dos cidadãos e, consequentemente, no cumprimento do seu papel na democracia.

Paralelamente a isso, vivemos tempos de crescimento das cidades que, por um lado, pressupõe desenvolvimento; por outro, acarreta novos problemas, como esgoto a céu aberto, calçamento esburacado, lâmpadas queimadas, coleta de lixo irregular, necessidades de creche e de postos de saúde, ausência de rede elétrica e água potável. Essas são situações que obrigam os indivíduos a se relacionarem de maneira mais próxima ao sentido de vizinhança, especialmente nos lugares em que esses problemas são mais graves, dando origem às conhecidas associações de moradores. Nesse complexo cenário, os indivíduos, juntos e com representação formal, têm mais força para cobrar dos órgãos responsáveis a ausência de infraestrutura, forçando melhorias públicas para o bairro.

O que temos, então, é um cenário marcado por duas características: moradores organizados e dispostos a fazer reivindicações, e veículos jornalísticos que não dão conta de retratar toda a complexidade dessa realidade e não se apresentam como alternativas viáveis de expressão para esses cidadãos. O jornalismo comunitário surge, assim, como instrumento de representação social, uma forma de expressão, um espaço que discute os valores e a identidade de um determinado grupo, ocupando uma lacuna deixada pela imprensa de grande porte.

\section{Revista ALTERJOR}

Grupo de Estudos Alterjor: Jornalismo Popular e Alternativo (ECA-USP)

Ano 10 Volume Ol Edição 23 Janeiro-Junho de 2021

Avenida Professor Lúcio Martins Rodrig̉ues, 443, Cidade Universitária, São Paulo, CEP: 05508-020 
A discussão sobre o caráter social que pode ser cumprido pelo jornalismo comunitário exige também um esforço acadêmico capaz de encontrar conceitos que auxiliam na árdua tarefa de oferecer elementos definidores do segmento e da prática. É fundamental que saibamos, afinal, de quem exatamente estamos falando, já que, não raro, o jornalismo comunitário acaba sendo confundido com o popular, o de serviços, o alternativo, o de bairro. De certa forma, ele dialoga com todas essas outras instâncias mas trilha também caminhos próprios e específicos, principalmente quando o contexto histórico que se impõe hegemonicamente é o da globalização neoliberal e o das grandes corporações midiáticas, como visto ao longo deste artigo.

O impulsionamento das formas de comunicação populares é um indicativo de que um novo projeto de sociedade pode estar sendo colocado em prática. Entretanto, os desafios ainda são muitos. É preciso disseminar a prática participativa da comunicação, que, como vimos, possibilita um processo educativo. É fundamental, também, que haja um salto no sentido do empoderamento desses veículos comunitários, para que os cidadãos possam ter nele uma peça-chave para a mudança real e efetiva de sua comunidade. Acreditamos que a maior qualidade do jornalismo comunitário é justamente a prática participativa. E para que as políticas públicas passem a, efetivamente, garantir um conjunto de melhores condições de vida para todos os cidadãos, é fundamental que esse legado transcenda para os espaços de poder e de decisão, e que exista um verdadeiro ideal participativo na gestão de todas as coisas que afetam a sociedade.

\section{REFERÊNCIAS}

AMARAL, Márcia. Jornalismo popular. São Paulo: Contexto, 2006.

BARBERO, Jesus Martín. Dos meios às mediações: comunicação, cultura e hegemonia. Rio de Janeiro: Editora UFRJ, 1997. 


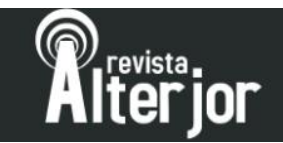

BELTRÁN, Luis Ramiro. Adeus a Aristóteles: comunicação horizontal. São Paulo: Cortez, 1981.

BOBBIO, Norberto. Dicionário de política. Brasília: Editora da Universidade de Brasília, 1998.

BOBBIO, Norberto. Estado, Governo, Sociedade: para uma teoria geral da política. Rio de Janeiro: Paz e Terra, 1986

BRASIL. Constituição (1988). Constituição da República Federativa do Brasil. Brasília, DF: Senado, 1988.

BRASIL. Lei $\mathrm{n}^{\mathrm{o}}$ 12.852, de 5 de agosto de 2013. Institui o Estatuto da Juventude e dispõe sobre os direitos dos jovens, os princípios e diretrizes das políticas públicas de juventude e o Sistema Nacional de Juventude. Diário Oficial da União. Brasília, DF, 6 de agosto de 2013. Seção 1, p. 3.

BUCCI, Eugenio. A imprensa e o dever da liberdade: a responsabilidade social do jornalismo em nossos dias. In: CANELA, Guilherme. (Org.). Políticas públicas sociais e os desafios para o jornalismo. São Paulo: Cortez, 2008.

DAHL, Robert. Sobre a democracia. Brasília: Editora da Universidade de Brasília, 2001.

DINES, Alberto. O papel do jornal e a profissão do jornalista. São Paulo: Summus Editorial, 2009.

GOODWIN, Doris Kearns. Lincoln. São Paulo: Record, 2003.

KAPLÚN, Mario. El comunicador popular. Buenos Aires: Humanitas, 1996.

KAPLÚN, Mario. Una pedagogía de la comunicacion. Madrid: Ediciones de la Torre, 1985.

KEANE, John. The media and democracy. Cambridge: Polity Press, 1998.

KUCINSKI, Bernardo. Jornalistas e revolucionários. São Paulo: Edusp, 2001.

MARCONDES FILHO, Ciro Juvenal Rodrigues. Quem manipula quem? São Paulo: Vozes, 1991.

MARCONDES FILHO, Ciro Juvenal Rodrigues. O capital da notícia. São Paulo: Ática, 1986.

MARX, Karl. Liberdade de imprensa. Porto Alegre: LPM, 2006.

MASCARO, Alysson. Estado e forma política. São Paulo: Boitempo, 2013.

MELO, José Marques de. Teoria do jornalismo: Identidades brasileiras. São Paulo: Paulus, 2006.

OLIVEIRA, Dennis de. Jornalismo alternativo: um potencial para a radicalização da democracia. Revista Signo y Pensamiento, v. XXX, p. 52-63, 2011.

OLIVEIRA, Dennis de. Jornalismo e emancipação: uma prática jornalística baseada em Paulo Freire. Curitiba: Appris, 2017. 


\section{Riejier}

PAIVA, Raquel. O espírito comum. São Paulo: Mauad, 2003.

PAIVA, Raquel; BARBALHO, Alexandre. (Orgs.). Comunicação e cultura das minorias. São Paulo: Paulus, 2005.

PATEMAN, Carole. Participação e teoria democrática. Rio de Janeiro: Paz e Terra, 1992.

PERUZZO, Cicilia M. K.; MOREIRA, Sonia Virgínia (orgs.). Intercom 25 anos. São Paulo: Intercom, 2002.

PERUZZO, Cicilia M. K. (Org.). Comunicação e outras culturas populares. São Paulo: Intercom, 1995.

PERUZZO, Cicilia M. K. Comunicação nos movimentos populares: a participação na construção da cidadania. São Paulo: Vozes, 1998.

PERUZZO, Cicilia M. K. (org.). Vozes cidadãs: aspectos teóricos e análises de experiências de comunicação popular e sindical na América Latina. São Paulo: Angellar, 2009. 